\title{
El derecho humano a la nacionalidad: perspectiva europea y latinoamericana ${ }^{1}$
}

\section{The Human Right to Nationality: European and Latin American Perspective}

\author{
Mercedes Soto Moya ${ }^{2}$ \\ Universidad de Granada (España)
}

Recibido: 27-05-18

Aprobado: 13-07-18

\section{Resumen}

A pesar de que la consideración de la nacionalidad como derecho humano no es una cuestión del todo pacífica, lo que resulta obvio es que, tanto los instrumentos internacionales de protección de los derechos humanos, como los propios tribunales encargados de controlar su efectiva aplicación, están limitando la competencia exclusiva de los Estados en esta materia. Aun cuando se reconozca el derecho de los Estados-nación a proteger su forma de vida, y el derecho de los nacionales, como pueblo soberano y constituyente, a establecer restricciones para el acceso a la ciudadanía a los extranjeros, estos derechos no son ilimitados.

Palabras-clave: Nacionalidad, Derechos Humanos, Europa, Latinoamérica

\footnotetext{
${ }^{1}$ Este artículo se enmarca en el Proyecto $\mathrm{I}+\mathrm{D}$, Movilidad internacional de personas: El impacto jurídico-social en España y en la UE de la adquisición de la nacionalidad española por la población inmigrante" (DER2016-75573-R), concedido por el Ministerio de Economía, Industria y Competitividad de España.

${ }^{2}$ (sotomoya@ugr.es). Profesora Titular del Departamento de Derecho internacional privado de la Universidad de Granada (España). Doctorado en Derecho comparado. Doctora en Derecho internacional privado con la tesis titulada: Las situaciones conyugales en el tráfico intracomunitario: un modelo de relación entre el Derecho internacional privado y el Derecho de extranjería, Editorial Universidad de Granada, 2007. Coordinadora del Máster en Derecho de extranjería de la Universidad de Granada. Entre sus publicaciones pueden destacarse: "La libre circulación de personas como concepto ambivalente", Revista Española de Derecho Internacional, 2008, pp. 163-178; "Libre circulación por el territorio de la UE de los matrimonios del mismo sexo celebrados en España", Revista de Derecho Comunitario Europeo, Vol. III, 2012, pp. 807-847; Uniones transfronterizas entre personas del mismo sexo,Tirant LoBlanch, España, 2013; "Prestación alimenticia en las relaciones hispano-argentinas", Boletín Mexicano de Derecho comparado, núm. 145, enero-abril 2016; "El Reglamento (UE) 2016/1104 sobre régimen patrimonial de las parejas registradas: algunas cuestiones controvertidas de su puesta en funcionamiento en el sistema español de DIPr", Revista Electrónica de Estudios Internacionales, no 35, junio 2018.
} 


\begin{abstract}
Although the consideration of nationality as a human right is not a matter of the whole peaceful, what is obvious is that both, the international instruments for the protection of human rights and the courts responsible for controlling their effective application, are limiting the exclusive competence of the States in this matter.Even if the right of Nation-States to protect their way of life is recognized, and the right of nationals, as sovereign and constituent people, to establish restrictions on access to citizenship for foreigners, these rights are not unlimited.
\end{abstract}

Key-words: Nationality, Human Rights,Europe, LatinAmerica.

\title{
1. Introducción: la nacionalidad como derecho humano
}

Aunque no resulta fácil determinar la naturaleza jurídica de la nacionalidad, sí se puede afirmar que ésta posee una característica esencial: es uno de los elementos jurídicos que configuran de manera más inmediata la identidad de las personas ${ }^{3}$. Y lo hace desde diferentes vertientes. No es solo el vínculo jurídico-político que liga a una persona física con su Estado ${ }^{4}$, ni la expresión jurídica de un hecho social ${ }^{5}$, ni un estado civil ${ }^{6}$, ni un criterio de conexión

${ }^{3}$ E. Rodríguez Pineau, "Identidad y nacionalidad", Anuario de la Facultad de Derecho de Madrid, $n^{\circ} 17,2013$, pp. 207-236, p. 207.

${ }^{4}$ Este vínculo jurídico-político que liga a una persona física con su Estado, permite distinguir a los súbditos propios de los que no lo son, esto es, los extranjeros, lo que entraña derechos y obligaciones diferentes respecto al Estado que otorga la cualidad de nacional a una persona, física o jurídica. Por todos véase, F. de Castro y Bravo, "La nationalité. La doublé nationalitée la supranationalité", Recueil des cours, vol. 102, 1961, pp. 546-550.

${ }^{5}$ La Corte Internacional de Justicia y la Comisión de Derecho Internacional, con más claridad, la han considerado como un vínculo jurídico que posee en su base un hecho social de cohesión, de adhesión, una unión efectiva de existencia, intereses y sentimientos, en donde los factores tales como la historia, la lengua, la religión, la cultura, juegan un rol preponderante, pero siempre variable, según las circunstancias dentro de ese conjunto de tradiciones y de idealescomunes (Commissiondu Droit International des NationsUnies, Rapportsur la Nationalité, 4 session, Genève, 1952, p. 7). La Corte Internacional de Justicia en famoso asunto Nottebohm la definió como "un vínculo jurídico basado en un hecho social de conexión, en una efectividad solidaria de existencia de intereses y sentimientos, unido a una reciprocidad de derechos y deberes" (Corte Internacional de Justicia (CIJ), Nottebohm (Liechtenstein v. Guatemala), Deuxièmephase: arrêt, Recueil, 1955, p. 23).

${ }^{6}$ Desde un punto de vista iusprivatista, la nacionalidad define la identidad de las personas porque les otorga un status civil, un conjunto de derechos y deberes (A. MAKAROV, Règles générales du droit de la nationalité, Recueil des Tours de l'Académie de Droit international, 1949, p. 281). Incluso hay autores que la consideran como un estado civil básico, ya que solo los nacionales ostentan la plenitud de derechos civiles. Como estado civil es una cualidad personalísima, intransferible tanto inter vivos como mortis causa. Afecta a la capacidad y a la responsabilidad de la persona frente a terceros (J. Carrascosa González, A, Durán Ayago y B. Carrillo Carrillo, Curso de nacionalidad y extranjería, Colex, Madrid, 2007, p. 19). 
esencial en las normas de conflicto ${ }^{7}$, sino que es algo más trascendente: una condición para poder acceder a derechos. En efecto, se puede considerar que la nacionalidad no es sólo una "concesión" del Estado -que determina quiénes son sus nacionales- sino que pasa a ser un derecho, y fundamental, pues es el que permite tener derechos. De este modo, la nacionalidad conferiría el "derecho a tener derechos".

No obstante, y a pesar de esto último, el que la nacionalidad sea o no un derecho humano no es una cuestión incontrovertida. Hay autores que consideran que la nacionalidad no tiene per se, en abstracto, la naturaleza de un derecho subjetivo9. Se esgrimen dos motivos. El primero es que no todos los ordenamientos la han configurado como un derecho fundamental. El segundo es que un derecho subjetivo confiere al individuo un poder jurídico para hacer valer un interés, por lo que su voluntad es necesaria para que el derecho exista. Y esto no sucede, por ejemplo, cuando el Estado confiere automáticamente la nacionalidad a todos los individuos que reúnan ciertos requisitos ${ }^{10}$. No compartimos esta consideración y sí, en cambio, la de parte de la doctrina cuando distingue dos dimensiones de la nacionalidad: ad intra y ad extra. Desde el primer punto de vista, cada Estado es soberano para legislar en materia de nacionalidad y para determinar las funciones que a ésta se le otorgan. Desde el segundo punto de vista, la nacionalidad -en los términos en que cada Estado la define- es utilizada por el Derecho internacional como un

\footnotetext{
${ }^{7}$ Pascual Estanislao Mancini fue el gran desarrollador de la nacionalidad como punto de conexión (aunque no se debe soslayar que este concepto ya había sido utilizado en el Código Civil Francés de Napoleón de 1804 y en el Código Civil Español de 1826). A raíz de su célebre discurso "Della nazionalità come fondamento del Diritto delle genti" dado en la Universidad de Turín el 22 de enero de 1851 con ocasión de la inauguración del Curso de Derecho Internacional en la capital piamontesa, editado en el mismo año por Eredi Botta en Turín y recientemente reeditado en dicha ciudad por Giappichelli (2000). En su célebre frase "la nacionalidad ha de seguir a la persona como la sombra al cuerpo" se resume su planteamiento principal: que toda Nación tenía derecho a convertirse en Estado y que, a tales fines, la comunidad internacional debería reconocer las normas que aquél dictara y aplicarlas a "todos sus nacionales", sin importar en qué lugar estuvieran esos nacionales. Aplica la idea tradicional aristotélica del Derecho de Gentes, para esbozar esta noción tan simple y sencilla pero tan compleja e importante.

${ }^{8}$ S. Hall, "The European Convention on Nationality and the Right to Have Rights", European Law Review, vol. 24, 1999, pp. 586-602, pp. 587-588.

${ }^{9}$ Ad exemplum, J. Carrascosa González: Derecho español de la nacionalidad. Estudio práctico, Comares, Granada, 2011, p. 7; B. Aláez Corral, Nacionalidad, ciudadanía y democracia, Centro de Estudios políticos y constitucionales, Madrid, 2006, p. 115 y ss. Entre los autores que sí consideran la nacionalidad como un derecho fundamental: L. Panella, La cittadinanza e le cittadinanz en el diritto internazionale, Editoriale Scientifica, Napoli, 2008, p. 76; A. Rubio Castro y M. Moya Escudero, "Nacionalidad y ciudadanía: una relación a debate", Anales de la Cátedra Francisco Suárez, no 37, 2003, pp. 105-153, p.130; J. Pereira Da Silva, Direitos de Cidadania e Direito à Cidadania. ACIME, Lisboa, 2004, pp. 90-102; S. Sánchez Lorenzo, "Derechos humanos y competencia exclusiva del Estado en materia de nacionalidad (La Sentencia de la Corte Interamericana de Derechos Humanos de 28 de agosto de 2014: caso Personas dominicanas y haitianas expulsadas c. República Dominicana)", REDI, Vol. 67, No. 2 (julio-diciembre 2015), pp. 111-133, p.117.

${ }^{10}$ B. Aláez Corral, Nacionalidad, ciudadanía y democracia, Centro de Estudios políticos...”, loc. cit., p. 115.
}

Araucaria. Revista Iberoamericana de Filosofia, Política, Humanidades y Relaciones Internacionales, año 20, ${ }^{\circ} 40$. Segundo semestre de 2018. Pp. 453-481. ISSN 1575-6823 e-ISSN 2340-2199 doi: 10.12795/araucaria.2018.i40.21 
instrumento de protección de la persona, dotándola así de una función ad extra. Por tanto en el orden internacional el esquema es muy simple: se consagra la nacionalidad como un derecho fundamental del individuo, en la medida en que constituye el principal vehículo que utiliza este ordenamiento para instrumentar la protección de los derechos humanos ${ }^{11}$.

Haciendo nuestra esta diferenciación se estructura el trabajo de la siguiente manera. En primer lugar, se estudia la competencia exclusiva de los Estados para legislar en materia de nacionalidad (dimensión ad intra). En segundo lugar, se analizan los límites que impone la nacionalidad como derecho humano a esta competencia exclusiva (dimensión ad extra), para finalizar, poniendo de relieve el difícil equilibrio entre la soberanía de los Estados y la garantía universal de los derechos desde una perspectiva jurisprudencial. Los asuntos que se analizan, tanto de la $\mathrm{CIDH}$, como del TEDH, e, incluso, del TJUE, desbordan, con mucho, las peculiaridades del caso concreto. Las implicaciones que derivan de sus argumentos invitan a una reflexión de la que extraeremos conclusiones más generales.

\section{El derecho humano a la nacionalidad como límite a la competencia exclusiva de los Estados}

La nacionalidad ha sido tradicionalmente concebida como un atributo adquirido por el individuo a partir del ejercicio de una potestad estatal. Pertenece a todo Estado soberano, regular por su propia legislación la adquisición de su nacionalidad así como conferir ésta por medio de la naturalización a través de sus propios órganos conforme a dicha legislación ${ }^{12}$. Cuando el Estado legisla en materia de nacionalidad se encuentra desvinculado de toda directriz imperativa. El Estado posee un poder exclusivo de atribución de su nacionalidad, tal y como fuere conocido desde tiempos de la antigua Corte Permanente de Justicia Internacional en el Caso de los Decretos de Nacionalidad entre Túnez y Marruecos, en su Opinión Consultiva del 7 de febrero de 1923"13. De esta suerte, todo Estado soberano posee, prima facie, una competencia propia para atribuir su nacionalidad. La nacionalidad define la relación de pertenencia del individuo a un Estado y también la situación de la persona frente a los demás Estados de los cuales no se disfruta la nacionalidad, para los que resulta un

\footnotetext{
${ }^{11}$ Por todos, J. M. Espinar Vicente, La nacionalidad y la extranjería en el sistema jurídico español, Civitas, Madrid,1994, pp. 37-38.

${ }^{12}$ Ya desde el Caso Notteböhm, 6 de Abril, 1955, Sentencia de la Corte Internacional de..., loc. cit.

${ }^{13}$ Décrets de nationalité promulgués en Tunisie et au Maroc, Ser. B, núm. 4, 1923, p. 24. CPJI, Questions de l'acquisition de la nationalité polonaise, Ser. B, núm. 7, 1924, p. 16; CPJI, Échange des populations grecques et turques, Ser. B, núm. 10, 1925, pp. 21-23. El Tribunal permanente de justicia internacional afirmaba que: "en el estado actual del Derecho internacional las cuestiones de nacionalidad están comprendidas, en la esfera de la competencia exclusiva de los Estados".
} 
extranjero. La nacionalidad delimita así la base personal del Estado, y sirve para precisar quiénes componen la "comunidad nacional".

En palabras de WEIL, "si el territorio determina los límites geográficos de la soberanía estatal, la nacionalidad determina los límites humanos. Más allá de estos límites hay territorio extranjero, soberanía extranjera y extranjeros"14. La nacionalidad es un instituto ligado a la proyección relacional del ordenamiento estatal frente a otros ordenamientos jurídicos territoriales y personales. Pertenece al núcleo duro de materias refractarias a toda unificación, persiste como irreductible, siempre bajo la competencia exclusiva de los Estados. Ni siquiera en la UE, espacio integrado en el que se reconoce una ciudadanía específica, se limita la competencia exclusiva del Estado en materia de nacionalidad. Los legisladores nacionales son autónomos a la hora de determinar las reglas de adquisición de su nacionalidad sin que el legislador UE pueda inmiscuirse en ello ${ }^{15}$. Nadie puede ser ciudadano de la Unión sin obtener previamente la nacionalidad de un Estado miembro de conformidad con la legislación de dicho Estado ${ }^{16}$. En efecto, porque aunque la ciudadanía de la Unión dimana de otra institución preexistente que es la nacionalidad, a la que complementa o se superpone ${ }^{17}$, estableciéndose un vínculo indisoluble entre la nacionalidad de un Estado miembro y la ciudadanía de la Unión, serán los Estados miembros quienes decidan quiénes son ciudadanos de la Unión al fijar en sus legislaciones internas los términos en los que se adquiere, se conserva o se pierde la nacionalidad ${ }^{18}$.

${ }^{14}$ P. Weil, "Access to Citizenship: a Comparison of Twenty Five Nationality Laws", Citizenship Today: Global Perspectives and Practices, Washington DC, Carnegie Endowment for International Peace, 2007, pp. 17-35, p.17.

${ }^{15}$ Y así lo ha establecido el TJCE en multitud de ocasiones, STJCE de 20 de febrero de 1975, as. C-21/74, Airola, vid. nota de L. Massaro, Columbia Journal of Transnational Law, 1976, pp. 514-537; STJCE de 20 de febrero de 1975, as. C-37/74, Van den Broeck; STJCE de 14 de diciembre de 1979, as. C-257/78, Kenny-Levick.

${ }^{16}$ Pero sí dejar de ser ciudadano de la Unión cuando el país del que es nacional deje de formar parte de la UE, como es el caso del Reino Unido. Por eso se ha registrado una propuesta de iniciativa ciudadana denominada "Ciudadanía de la UE para los europeos: unidos en la diversidad a pesar del ius soli y el ius sanguinis", que pretende que se garantice, en caso de retirada de un Estado miembro, a los ciudadanos de ese país, poder seguir beneficiándose de derechos similares a los que disfrutaban cuando dicho país era un Estado miembro. Decisión (UE) 2017/599 de la Comisión, de 22 de marzo de 2017.

${ }^{17}$ En palabras de E. Pérez Vera "precisamente la originalidad de la ciudadanía europea está en que surge como una especie de supranacionalidad, como un tertiumgenus entre la nacionalidad y la extranjería", (vid. "La ciudadanía europea en el Tratado de Maastricht. Hacia un Nuevo orden internacional y europeo", Homenaje al Profesor Diez de Velasco, Madrid, Tecnos, 1993, pp. 1123-1148).

${ }^{18}$ Todo esto implica, por una parte, que la ciudadanía va a seguir los avatares de la nacionalidad que le sirve de base; por otra, que la existencia de otros vínculos entre las personas y la Unión, por fuertes que sean (como la residencia prolongada, la relación familiar con un ciudadano o el nacimiento en territorio de la Unión, por ejemplo) no permiten acceder a la ciudadanía. A su vez, su atribución automática a quien posee la nacionalidad de un Estado miembro supone que no es posible renunciar a ella, conservando la nacionalidad que le sirve de base, ni puede ser adquirida al margen de la nacionalidad de un Estado miembro (E. Pérez Vera, "Ciudadanía y nacionalidad de los Estados miembros", Revista de Derecho de la Unión Europea, n² 27-28, 2014, pp. 217-230). 
No obstante, la evolución del Derecho internacional ha llevado a que esta concepción estatalista, sin desaparecer totalmente, se vea limitada por la normativa de derechos humanos. En la actualidad, el reconocimiento de la nacionalidad no depende de la pura discrecionalidad estatal. En efecto, en materia de derechos humanos, el legislador que regula, reconoce y desarrolla derechos fundamentales dispone de un margen de actuación acotado, de un lado, a su vinculación efectiva al cuadro de derechos reconocidos en la Constitución estatal, y de otro, al contenido de las obligaciones adoptadas en sus relaciones internacionales, y a los textos en que se plasman dichas relaciones ${ }^{19}$.Tanto la Declaración Universal de Derechos Humanos de 10 de diciembre de 1948, como el Pacto Internacional de Derechos Civiles y Políticos de 19 de diciembre de 1966, como la Convención sobre los Derechos del niño de 20 de noviembre de 1989, Convención sobre la reducción de los casos de apatridia de 30 de agosto de 1961, como la Declaración Americana de Derechos y Deberes del Hombre de 30 de abril de 1948, por citar algunos de los instrumentos más relevantes, reconocen al individuo el derecho a tener una nacionalidad ${ }^{20}$. No se puede obviar, no obstante, que estos instrumentos presentan varios inconvenientes. Por un lado, su frecuente carácter non self-executing, y, por otro, el modo abstracto en que realizan una consagración del derecho, sin determinar qué Estado está obligado a otorgar la nacionalidad. No obstante, los derechos humanos como mínimo moral, como núcleo de la justicia a nivel nacional e internacional, imponen a los Estados democráticos restricciones ${ }^{21}$.Aun cuando se reconozca el derecho de los Estados-nación a proteger su forma de vida, y el derecho de los nacionales, como pueblo soberano y constituyente, a establecer límites para el acceso a la ciudadanía a los extranjeros, estos derechos no son ilimitados.

19 J. M. Goig Martínez, "Regularización y naturalización de inmigrantes irregulares en República Dominicana. Estudio de la Sentencia 0168/13 del Tribunal Constitucional dominicano y sus efectos en materia de nacionalidad", Anuario Iberoamericano de Justicia Constitucional, núm. 19, Madrid, 2015, págs. $185-219$.

${ }^{20}$ El artículo 15 de la DUDH establece: "1. Toda persona tiene derecho a una nacionalidad. 2. A nadie se privará arbitrariamente de su nacionalidad ni del derecho a cambiar de nacionalidad". El art. 24.3 del Pacto Internacional de Derechos Civiles y Políticos también menciona el derecho a la nacionalidad, aunque solo en relación con la infancia: "todo niño tiene derecho a adquirir una nacionalidad". Del mismo modo, el artículo 70 de la Convención sobre los Derechos del Niño dispone: “1. El niño será inscripto inmediatamente después de su nacimiento y tendrá derecho desde que nace a... adquirir una nacionalidad.." El art. 1.1 de la Convención sobre la reducción de los casos de apatridia establece que: "todo Estado contratante concederá su nacionalidad a la persona nacida en su territorio que de otro modo sería apátrida". Igualmente, el art. 4.1 dispone: "todo Estado contratante concederá su nacionalidad a una persona que no haya nacido en el territorio de un Estado contratante y que de otro modo sería apátrida si en el momento del nacimiento del interesado uno de los padres tenía la nacionalidad del primero de esos Estados”. El artículo XIX de la Declaración Americana de Derechos y Deberes del Hombre preceptúa: "toda persona tiene derecho a la nacionalidad que legalmente le corresponda y el de cambiarla, si así lo desea, por la de cualquier otro país que esté dispuesto a otorgársela".

${ }^{21}$ A. Rubio Castro y M. Moya Escudero, "Nacionalidad y ciudadanía: una relación a debate", Anales de la Cátedra Francisco Suárez, n 37, 2003, pp. 105-153, p. 150. 
De esta manera, la determinación de quiénes son nacionales sigue siendo competencia interna de los Estados. Sin embargo, su discrecionalidad en esa materia sufre un constante proceso de restricción conforme a la evolución del Derecho internacional, con vistas a una mayor protección de la persona frente a la arbitrariedad de los Estados. Estas restricciones provienen, en su mayoría, tanto de los instrumentos internacionales de protección de los derechos humanos, como de los tribunales encargados de controlar su efectiva aplicación.

El primer límite deriva del derecho de todo individuo a ostentar una nacionalidad. Sobre este derecho se justifican los principios y las normas de Derecho internacional destinados a prevenir o evitar, por ejemplo, las situaciones de apatridia. El segundo es el derecho a no ser privado arbitrariamente de la nacionalidad que ya se posee. Está relacionado con el derecho a tener una nacionalidad pero no es exactamente igual, ya que podría haber una privación arbitraria de nacionalidad que no dejara al individuo en situación de apatridia (por ejemplo, porque se tratara de un individuo con doble nacionalidad que solo fuera privado de una de ellas) $)^{22}$.El derecho de la persona a no ser privada de su nacionalidad no es un derecho absoluto. La DUDH solo prohíbe la privación de nacionalidad que sea arbitraria. El Estado podría entonces privar a una persona de su nacionalidad, siempre que lo hiciera de modo no arbitrario. Según lo ha sostenido el secretario general en el informe presentado a solicitud del Consejo de Derechos Humanos de las Naciones Unidas: "la privación de nacionalidad debe hacerse de conformidad con el derecho interno y respetando los estándares mínimos del derecho internacional. Los estándares internacionales referidos están vinculados a la existencia de una finalidad compatible con los derechos humanos y de una relación de proporcionalidad entre la medida de privación de nacionalidad y esa finalidad"23. El tercer límite está relacionado con la prohibición de privar a una persona de modo arbitrario de la posibilidad de cambiar de nacionalidad. Es el derecho a que no se pongan obstáculos a la obtención de una nacionalidad cuando exista un Estado que esté dispuesto a darla $^{24}$. El cuarto límite para los Estados es el de no discriminación por razón

\footnotetext{
${ }^{22}$ Comparte esta opinión F. Arletazz, "La nacionalidad en el derecho internacional americano", Anuario Mexicano de Derecho Internacional, vol. XV, 2015, pp. 413-447, p.419.

${ }^{23}$ Secretario General de las Naciones Unidas, Human Rights and ArbitraryDeprivation of Nationality, 14 de diciembre de 2009, A/HRC/13/34, párr. 24-25.

${ }^{24}$ Un caso paradigmático es el asunto Estiverne (Resolución núm. 20/88, caso 9855 (Haití), 24 de marzo de 1988), relativo a un haitiano que se había exiliado en Estados Unidos durante la dictadura de Duvalier. Al adquirir la nacionalidad estadounidense había perdido la nacionalidad haitiana. Según la Constitución haitiana de 1987, sin embargo, quienes hubiesen perdido la nacionalidad podrían recuperarla por una simple manifestación ante el Ministerio de Justicia. A pesar de formular esta declaración, el señor Estiverne no recuperó su nacionalidad. Además, se decretó una orden de expulsión en su contra. La Comisión halló una violación a las normas sobre nacionalidad. Aunque no lo dijo expresamente, hay que entender que el derecho vulnerado fue el derecho a cambiar de nacionalidad, ya que Haití reconocía tal derecho en su Constitución pero puso obstáculos ilegítimos al cambio efectivo (vid. F. Arletazz, "La nacionalidad en el derecho internacional americano", Anuario Mexicano de Derecho..., loc. cic., p. 433).
} 
de raza o sexo. El principio de derecho imperativo de protección igualitaria y efectiva de la ley y no discriminación determina que los Estados, al regular los mecanismos de otorgamiento de la nacionalidad, deben abstenerse de producir regulaciones discriminatorias o que tengan efectos discriminatorios en los diferentes grupos de una población al momento de ejercer sus derechos ${ }^{25}$.

Sobre estos cuatro límites pivota la jurisprudencia de los tribunales internacionales de derechos humanos, cuando se enfrentan a casos vinculados a la tensión entre la soberanía estatal y la consideración de la nacionalidad como derecho humano. Analizaremos varios asuntos paradigmáticos de ambos lados del Atlántico, tanto de la Corte Interamericana de Derechos Humanos (CIDH) como del Tribunal Europeo de Derechos Humanos (TEDH), e, incluso, del Tribunal de Justicia de la Unión Europea (TJUE), seleccionados por su importancia, y, que desbordan, con mucho, las peculiaridades del caso concreto.

\section{El difícil equilibrio entre la soberanía de los Estados y la garantía universal de los derechos: perspectiva jurisprudencial}

\section{A. Jurisprudencia de la Corte Interamericana de Derechos Humanos}

La Corte Interamericana de Derechos Humanos(CIDH) se ha pronunciado sobre el derecho a tener una nacionalidad, la apatridia y su vinculación con el goce y ejercicio de derechos humanos en varios asuntos ${ }^{26}$. Hemos escogido para su análisis los casos de las niñas Yean y Bosico y el Caso de personas dominicanas y haitianas expulsadas, ambos, contra República Dominicana ${ }^{27}$. También nos ha parecido relevante la Opinión Consultiva sobre naturalización solicitada por Costa Rica al $\mathrm{CIDH}^{28}$.

${ }^{25}$ La Convención sobre la Eliminación de Todas las Formas de Discriminación contra la Mujer adoptada por la Asamblea General de las Naciones Unidas el 18 de diciembre de 1979, contiene un artículo específico relativo a la no discriminación de la mujer en materia de nacionalidad. Según el artículo 90.: 1. Los Estados Partes otorgarán a las mujeres iguales derechos que a los hombres para adquirir, cambiar o conservar su nacionalidad. Garantizarán, en particular, que ni el matrimonio con un extranjero ni el cambio de nacionalidad del marido durante el matrimonio cambien automáticamente la nacionalidad de la esposa, la conviertan en apátrida o la obliguen a adoptar la nacionalidad del cónyuge. 2. Los Estados Partes otorgarán a la mujer los mismos derechos que al hombre con respecto a la nacionalidad de sus hijos.

${ }^{26}$ Aunque existen otras decisiones que también se han ocupado de estas cuestiones. Por ejemplo, Caso Castillo Petruzzi y otros vs. Perú, resuelto con sentencia de fecha 30 de mayo de 1999 o el Caso IvcherBronstein vs. Perú, resuelto con sentencia de 6 de febrero de 2001. Véase para un análisis de estos pronunciamientos, M. F. del Rosario Rodríguez, "El Derecho a la nacionalidad", Revista Internacional de Derechos Humanos, 2011 Año I, no 1, pp. 81-107.

${ }_{27}$ Corte IDH. Caso de las niñas Yean y Bosico VS. República Dominicana. Sentencia de 8 de septiembre de 2005. Serie C No. 130; Corte IDH. Caso de personas dominicanas y haitianas expulsadas Vs. República Dominicana. Excepciones Preliminares, Fondo, Reparaciones y Costas. Sentencia de 28 de agosto de 2014. Serie C No. 282.

${ }^{28}$ Corte IDH. Propuesta de modificación a la Constitución Política de Costa Rica relacionada con 
Comenzando por esta Opinión Consultiva, el Gobierno de Costa Rica requirió a la $\mathrm{CIDH}$ para que evaluara la compatibilidad de dos proyectos de reforma constitucional en materia de naturalización con la Convención Americana y, específicamente, con sus artículos 20 (derecho a tener una nacionalidad), 17.4 (igualdad de los cónyuges) y 24 (igualdad ante la ley).La Corte comienza recordando, para que no haya lugar a confusión que: "aunque tradicionalmente se ha aceptado que la determinación y regulación de la nacionalidad son competencia de cada Estado, la evolución cumplida en esta materia nos demuestra que el derecho internacional impone ciertos límites a la discrecionalidad de los Estados y que, en su estado actual, en la reglamentación de la nacionalidad no sólo concurren competencias de los Estados sino también las exigencias de la protección integral de los derechos humanos"29.

Como criterio general, la Corte sostuvo que el derecho a la nacionalidad, reconocido por el artículo 20 de la Convención, no estaba afectado por los proyectos de reforma constitucional objeto de la consulta. En efecto, el hecho de que los Estados endurezcan las condiciones de adquisición de la nacionalidad no provoca de por sí una violación del artículo 20, en tanto ese endurecimiento no implique privar arbitrariamente de la nacionalidad a personas que ya la han adquirido, negar la nacionalidad a quien según el artículo 20 tiene un derecho a obtenerla o frustrar el derecho a cambiar de nacionalidad. Tampoco contraviene el citado artículo la posibilidad de otorgar la nacionalidad por residencia incorporando un criterio de mayor vinculación con los valores e intereses de la sociedad del Estado otorgante En este aspecto la Corte consideró que: "no puede ponerse en duda la potestad soberana de Costa Rica para resolver sobre los criterios que han de orientar el discernimiento o no de la nacionalidad a los extranjeros que aspiran a obtenerla, ni para establecer ciertas diferencias razonables con base en circunstancias de hecho que, por razones objetivas, aproximen a unos aspirantes más que a otros al sistema de valores e intereses de la sociedad costarricense". Para la Corte IDH, por tanto, la adhesión a principios y valores estatales puede justificar políticas que establezcan requisitos menos estrictos para aquellos que compartan lazos históricos comunes. El hecho de que una determinada reforma responda a una reacción nacionalista, a una tendencia regresiva frente al espíritu tradicionalmente humanitario de un sistema jurídico o a un rechazo a una tradición de unidad de determinados pueblos no es algo sobre lo que ella deba pronunciarse ${ }^{30}$. Se trata de cuestiones políticas que caen dentro de la competencia del Estado, y que escapan a la consideración estrictamente jurídica a la que ella debe atenerse.

la naturalización. Opinión Consultiva OC-4/84 de 19 de enero de 1984.

${ }^{29}$ Ibídem, párr. 32.

${ }^{30}$ Ibidem, párr. 39 y 40.

Araucaria. Revista Iberoamericana de Filosofia, Politica, Humanidades y Relaciones Internacionales, año 20, $\mathrm{n}^{\circ} 40$. Segundo semestre de 2018. Pp. 453-481. ISSN 1575-6823 e-ISSN 2340-2199 doi: 10.12795/araucaria.2018.i40.21 
En España, por ejemplo, existe un régimen especial aplicable a quienes proceden de países o comunidades con una particular vinculación con aquél país. El artículo 22 Código Civil establece un periodo de residencia reducido de dos años (cuando la regla general son diez) para los nacionales de ciertos países, además de eximirles del requisito de tener que renunciar a su nacionalidad anterior. Se trata de los nacionales de origen de países iberoamericanos, Andorra, Filipinas, Guinea Ecuatorial, Portugal y los sefardíes. Existe un triple criterio para establecer esa relación especial: a) los Estados que nunca han sido colonias españolas pero han estado unidas en el pasado a España, como Portugal y Andorra; b) los países que fueron incorporados al imperio español o fueron colonias españolas, entre los que se distinguen los que se incorporaron en tiempos más remotos, como los países iberoamericanos y Filipinas, y las que lo fueron en tiempo más reciente, como Guinea Ecuatorial y c) aquellas comunidades que no forman un Estado, caso de los sefardíes ${ }^{31}$. En este último supuesto la Ley 12/2015, de 24 de junio, en materia de concesión de la nacionalidad española a los sefardíes originarios de España, introduce un nuevo cauce de adquisición de la nacionalidad española y los exime incluso de tener que demostrar los dos años de residencia continuada, legal e inmediatamente anterior a la solicitud ${ }^{32}$. Parece que en este sentido, la atribución de la nacionalidad por residencia con un plazo reducido, o incluso, sin necesidad de un período mínimo de residencia, no iría en contra del principio de no discriminación e igualdad,

${ }^{31}$ Se denomina sefardíes a los judíos que vivieron en la Península Ibérica y a sus descendientes que, tras los Edictos de 1492, optaron por la expulsión ante la alternativa de la conversión forzosa al catolicismo, dispersándose fundamentalmente por el norte de África, los Balcanes y el Imperio Otomano. Su denominación procede de la voz "Sefarad", España en lengua hebrea.Los hijos de Sefarad conservaron muchas de las costumbres y el idioma ladino o la haketía, español primigenio enriquecido con los préstamos de los idiomas de acogida. Y mantuvieron a España -Sefarad- en su memoria, a pesar del injusto trato que recibieron. Esta Ley pretende ser el punto de encuentro entre los españoles de hoy y los descendientes de quienes fueron injustamente expulsados a partir de 1492, y se justifica en la común determinación de construir juntos, frente a la intolerancia de tiempos pasados, un nuevo espacio de convivencia y concordia, que reabra para siempre a las comunidades expulsadas de España las puertas de su antiguo país.Vid. M. VARGAS GÓMEZ-URRUTIA, "Shalom Sefarad: Una "erensya" envenenada", Parte I y Parte II, Bitácora Millennium DIPr: Derecho Internacional Privado, $\mathrm{N}^{\circ}$. 2, 2015, y toda la doctrina allí citada.

${ }^{32}$ Además delas pruebas de idioma (DELE A2 o superior) y de conocimientos constitucionales y socioculturales de España (CCSE), deberán aportarse, en primer lugar, los documentos que acrediten el origen sefardí. La enumeración no es cerrada, debiendo ser valorados los documentos en su conjunto por el Notario. Se requieren dos certificados: a) Certificado expedido por el Presidente de la Comisión Permanente de la Federación de Comunidades Judías de España.; o b) Certificado expedido por el presidente o cargo análogo de la comunidad judía de la zona de residencia o ciudad natal del interesado y certificado de la autoridad rabínica competente reconocida legalmente en el país de residencia habitual de solicitante. En segundo lugar, los documentos que acrediten la especial vinculación con España. Por ejemplo: estar casado con un/a nacional español/a, acreditar parentesco en línea directa con un nacional español, tener acciones en una empresa española..... Véase la Instrucción de 29 de septiembre de 2015, de la Dirección General de los Registros y del Notariado, sobre la aplicación de la Ley 12/2015, de 24 de junio, en materia de concesión de la nacionalidad española a los sefardíes originarios de España.

Araucaria. Revista Iberoamericana de Filosofía, Política, Humanidades y Relaciones Internacionales, año 20, $\mathrm{n}^{\circ} 40$. Segundo semestre de 2018. Pp. 453-481. ISSN 1575-6823 e-ISSN 2340-2199 doi: 10.12795/araucaria.2018.i40.21 
siempre que se pueda justificar en la adhesión a principios y valores estatales de países con los que se compartan lazos históricos ${ }^{33}$.

Por lo que respecta a los controvertidos pronunciamientos de la CIDH ("Niñas Yean y Bosico" y "Personas haitianas y dominicanas expulsadas"), de 8 de septiembre de 2005 y 28 de agosto de 2014, respectivamente, la Corte sí consideró conculcado, entre otros, el artículo 20 de la Convención por parte de la República Dominicana ${ }^{34}$. En concreto, por la no atribución de la nacionalidad por ius soli a hijos de padres haitianos en situación irregular.

No obstante, antes de analizar las consideraciones de la Corte IDH en los casos dominicanos, creemos imprescindible realizar una mínima contextualización ${ }^{35}$. La migración haitiana hacia República Dominicana se inicia a comienzos de la década de 1920 con grandes desplazamientos de población para trabajar en los campos azucareros.Con el tiempo, esta última decayó, y el Estado dominicano permitió la residencia en situación irregular de nacionales haitianos que se asentaron en República Dominicana de manera permanente y formaron sus familias con hijos y nietos (segunda y tercera generación), quienes nacieron y han residido en República Dominicana. La mayoría de estas personas vive en condiciones de extrema pobreza, asentados como braceros en "bateyes", poco a poco erigidas en comunidades permanentes, muchas veces marginales ${ }^{36}$. Uno de los mayores problemas $-\mathrm{y}$ es en el que se centran los supuestos que analizamos- es el acceso a documentación de identificación. Los nacionales

${ }^{33}$ Aunque no podemos detenernos en realizar un análisis exhaustivo de la situación de los saharauis en relación con España, sí consideramos obligado preguntarnos si existe una discriminación en relación a todos los demás nacionales de los países enumerados supra, y si no iría la postura adoptada por las autoridades españolas en contra del principio de no discriminación e igualdad. Para un análisis en profundidad puede verse la importante Sentencia de la Sala de lo Civil del Tribunal Supremo español sobre la cuestión de la nacionalidad española de los saharauis, de 28 de octubre de 1998 (BOE de 20 de noviembre de 1998). Pueden verse también los diferentes trabajos de J. Soroeta Liceras, en especial, "La problemática de la nacionalidad de los habitantes de los territorios dependientes y el caso del Sáhara Occidental", Anuario español de derecho internacional, No 15, 1999, pp. 645-676; id. "Jurisprudencia española en materia de Derecho internacional público - Comentarios de sentencias La condición jurídica de los saharauis: nacionalidad, apatridia y asilo", Revista Española de Derecho Internacional, Vol. 66, № 2, 2014, pp. 226-237; F. Gómez Recio, "Sobre la nacionalidad española de los naturales del Sahara", La Ley, núm. 7333, 2010; J. Ferrer Lloret, "El conflicto del Sahara Occidental ante los Tribunales de la Unión Europea", Revista General de Derecho Europeo, núm. 42, 2017, pp. 15-64; J. J. Pérez Milla, "Travesía hacia la nacionalidad española: oasis y desiertos en el Sahara", Revista General de Legislación y Jurisprudencia, 2011, pp. 417-454.

${ }^{34}$ El revuelo mediático y político y la controversia surgida después del fallo de la CIDH puede verse resumido en S. Sánchez Lorenzo, "Derechos humanos y competencia exclusiva del Estado en materia de nacionalidad"..., loc. cit.

${ }^{35}$ La historia de las relaciones entre Haití y la República Dominicana es particularmente compleja. Mientras que Haití obtuvo su independencia de Francia en 1803, lo que es hoy la República Dominicana se independizó originalmente de España en noviembre de 1821. Esta primera República, llamada "Haití Español", apenas pudo mantenerse tres meses. En febrero de 1822 Haití ocupó la parte oriental de la isla. Dos décadas más tarde, en febrero 1844, se produce la independencia dominicana, cuya guerra termina en 1854.

${ }^{36}$ C. Núñez Donald, "La jurisprudencia de la Corte Interamericana de Derechos Humanos frente a la movilidad humana: entre cosmopolitismo y hospitalidad”, Universitas, 2018, n 27, pp. 76-109.

Araucaria. Revista Iberoamericana de Filosofia, Política, Humanidades y Relaciones Internacionales, año 20, ${ }^{\circ} 40$. Segundo semestre de 2018. Pp. 453-481. ISSN 1575-6823 e-ISSN 2340-2199 doi: 10.12795/araucaria.2018.i40.21 
haitianos y dominicanos de ascendencia haitiana -en su mayoría-recurren al procedimiento de declaración tardía de nacimiento para declarar a sus hijos/as nacidos, considerando que las madres dan a luz en el hogar y por el temor a ser expulsados al estar en presencia de funcionarios del hospital o la policía.

Pues bien, partiendo de esta realidad, los hechos del caso son los siguientes. Las menores, Dilcia Oliven Yean y Violeta Bosico Cofi, eran hijas de padres haitianos indocumentados. A pesar de que les correspondía la nacionalidad dominicana, les fue negada a ambas la inscripción tardía y, como consecuencia, sus actas de nacimiento dominicanas. Por este motivo, y una vez agotados los recursos internos, las menores y sus representantes acudieron al sistema Interamericano de Derechos Humanos. El resultado final fue la sentencia Yean y Bosico, que encontró responsable al Estado dominicano de violentar los derechos de las menores. En República Dominicana la nacionalidad (en el momento en que ocurren los hechos) se regía por el principio de ius soli, con la excepción de hijos/as de personas en representación diplomática y personas transeúntes. Por tanto, parecería claro que a estas niñas se les debería haber atribuido la nacionalidad dominicana por ius soli. No obstante, la nacionalidad fue denegada por considerar a sus padres - trabajadores migratorios haitianos en situación irregular- como transeúntes, haciendo un ejercicio de funambulismo interpretativo de la ley, lo que dio lugar al pronunciamiento de la CIDH sobre el asunto. La Corte afirmó que: "para considerar a una persona como transeúnte o en tránsito, independientemente de la clasificación que se utilice, el Estado debe respetar un límite temporal razonable, y ser coherente con el hecho de que un extranjero que desarrolla vínculos en un Estado no puede ser equiparado a un transeúnte o a una persona en tránsito" 37 .

Como consecuencia de este pronunciamiento y, en nuestra opinión, para evitar en un futuro hacer una interpretación tan forzada de la ley, en el año 2010 se reformó la Constitución dominicana. Se añadió a las excepciones del ius soli la referida a las "hijas o hijos de extranjeros que residan ilegalmente en territorio dominicano" (art. 18.3 Constitución dominicana). A sensu contrario: solo se atribuiría ex lege la nacionalidad a aquellas personas nacidas en República Dominicana de padres en situación administrativa regular. Y, precisamente, esta reforma constitucional es la que dio lugar al segundo pronunciamiento de la CIDH al que hacíamos referencia supra: el "caso de las personas haitianas y dominicanas expulsadas", de 28 de agosto de 2014. La sentencia, en concreto, trae causa en la detención arbitraria y expulsión sumaria del territorio de República Dominicana de presuntas víctimas haitianas y dominicanas de ascendencia haitiana, incluidos niñas y niños, sin el seguimiento del procedimiento de expulsión normado en el Derecho interno. En particular, la Comisión consideró que existían una serie de impedimentos para que los

\footnotetext{
${ }^{37}$ Ver Yean y Bosico, $\$ 157$.
}

Araucaria. Revista Iberoamericana de Filosofía, Política, Humanidades y Relaciones Internacionales, año 20, $\mathrm{n}^{\circ} 40$. Segundo semestre de 2018. Pp. 453-481. ISSN 1575-6823 e-ISSN 2340-2199 doi: 10.12795/araucaria.2018.i40.21 
migrantes haitianos pudieran inscribir a sus hijos e hijas nacidos en territorio dominicano, y para la obtención de la nacionalidad dominicana por parte de las personas de ascendencia haitiana nacidas en la República Dominicana.

La Corte obligó a la República Dominicana a derogar el artículo 18.3 de su Constitución que condiciona, como hemos señalado, la atribución del ius soli al hecho de que al menos uno de los progenitores resida legalmente en territorio dominicano. Considera que esta disposición es contraria al Derecho internacional por vulnerar los límites de la competencia estatal en materia de nacionalidad: "la adquisición de la nacionalidad en virtud del ius soli resulta discriminatoria y por lo tanto vulnera el artículo 24 convencional". Añadiendo que "el estatus migratorio de una persona no se transmite a sus hijos", de forma que "la aplicación de este criterio, priva a las personas de seguridad jurídica en el disfrute de derecho a la nacionalidad [...], lo que vulnera los arts. 3, 18 y 20 de la Convención, y por el conjunto de esas violaciones, el derecho a la identidad"38.

Es imprescindible poner de relieve que República Dominicana no solo no acató el fallo de la Corte, sino que como consecuencia de esta condena, el TC dominicano declaró la inconstitucionalidad del Instrumento de Aceptación de la Competencia de la Corte Interamericana de los Derechos Humanos (CIDH) suscrito el 19 de febrero de 1999, por lo que desvincula al país de las decisiones de ese organismo regional ${ }^{39}$.De todas formas República Dominicana no es el único país que ha cambiado su postura acerca de la obligatoriedad de las sentencias de la CIDH. La Corte Suprema argentina, en el caso "Fontevecchia", sostuvo que, si bien las decisiones de la Corte Interamericana son "en principio" de cumplimiento obligatorio, no deberían ser cumplidas si el tribunal interamericano actúo en exceso de su competencia, o bien cuando la condena es de cumplimiento imposible por contradecir "principios de derecho público constitucional argentino" ${ }^{40}$. Por el contrario, también hay países que no solo acatan las decisiones de la CIDH que le afectan directamente, sino que toman nota de los pronunciamientos que afectan a otros Estados para modificar su legislación sobre nacionalidad. Este ha sido el caso, por ejemplo, de Chile, que ha utilizado los criterios de las sentencias respecto de República Dominicana para modificar la interpretación de la normativa interna y prevenir los posibles casos de apatridia ${ }^{41}$.

\footnotetext{
${ }^{38}$ Caso de personas dominicanas y haitianas expulsadas Vs. República Dominicana, $§ 264$.

39 En el año 1999, la República Dominicana, mediante el "Instrumento de Aceptación de laCompetencia de la Corte Interamericana de Derechos Humanos" del 19 de abril de 1999, reconoció la competencia de la Corte IDH, de acuerdo con lo previsto por la CADH.

${ }^{40}$ Sentencia de 14 de febrero de 2017, Ministerio de Relaciones Exteriores y Culto s/ informe sentencia dictada en el caso "Fontevecchia y D'Amico vs. Argentina" por la Corte Interamericana de Derechos Humanos, considerando 12. Véase un comentario en V. Abramovich, "Comentarios sobre "Fontevecchia",la autoridad de las sentencias de la Corte Interamericana y los principios de derecho público argentino", Pensamiento Penal, marzo 2017, pp. 1-17.

${ }^{41}$ Véase: INDH. Informe sobre la situación de derechos humanos en Chile. Santiago, 2016, pp. $41-55$.
}

Araucaria. Revista Iberoamericana de Filosofia, Política, Humanidades y Relaciones Internacionales, año 20, $\mathrm{n}^{\circ} 40$ Segundo semestre de 2018. Pp. 453-481. ISSN 1575-6823 e-ISSN 2340-2199 doi: 10.12795/araucaria.2018.i40.21 
Si hemos calificado como significativa esta jurisprudencia es porque del análisis concreto de estos dos pronunciamientos se puede extraer una conclusión relevante: la CIDH ha puesto ciertos límites a la soberanía estatal considerando la nacionalidad como un derecho humano, estableciendo que los Estados tienen la obligación de no adoptar prácticas o legislación, respecto al otorgamiento de la nacionalidad, cuya aplicación favorezca el incremento del número de personas apátridas, condición que es derivada de la falta de nacionalidad. La apatridia ocasiona una extrema vulnerabilidad. Además, la condición migratoria irregular de los progenitores no puede ser en ningún caso un requisito para la atribución de la nacionalidad vía ius soli.Para la Corte Interamericana de Derechos Humanos, la nacionalidad es la expresión jurídica de un hecho social de conexión de un individuo con un Estado. Se trata de un derecho fundamental e inderogable de la persona humana, ya que permite que un individuo adquiera y ejerza los derechos y responsabilidades propias de la pertenencia a una comunidad política. Como tal, la nacionalidad es un prerrequisito para el ejercicio de determinados derechos ${ }^{42}$.

A colación del análisis de ambos pronunciamientos de la CIDH la pregunta es pertinente: ¿resulta obligatorio para los Estados, entonces, acatar el criterio del ius soli? La respuesta es clara: los Estados pueden establecer libremente los criterios bajo los cuales reconocen la nacionalidad. El régimen constitucional y legal de cada Estado puede aceptar indistintamente el principio del ius soli o del ius sanguinis, o mezclarlos ${ }^{43}$. Casi ningún Estado utiliza uno de los criterios con exclusión absoluta del otro, pero sí prefiere uno u otro según cual sea la finalidad política que le atribuya a la nacionalidad: básicamente conservar como nacionales a los emigrantes y a sus hijos (ius sanguinis), o integrar en la Nación al máximo número de inmigrantes llegados y nacidos en el territorio del Estado (ius soli) ${ }^{44}$. La casuística y el desarrollo pormenorizado de las normas reguladoras de la nacionalidad desvelan la extraordinaria importancia que ésta tiene para el Estado, así como su fuerte trasfondo político. El predominio del ius sanguinis o del ius soli no hace sino poner de relieve que no existe Estado

42 Entre otras, Corte Interamericana de Derechos Humanos, Caso IvcherBronstein vs. Perú. Sentencia de 6 de febrero de 2001; Opinión Consultiva OC-4/84 del 19 de enero de 1984 (solicitada por el Gobierno de Costa Rica). Corte Interamericana de Derechos Humanos, Caso Castillo Petruzzi y otros vs. Perú. Sentencia de 30 de mayo de 1999. Corte Interamericana de Derechos Humanos, Caso Yean y Bosico vs. República Dominicana, sentencia de 8 de septiembre de 2005

${ }^{43}$ Hay autores que consideran que la crisis del concepto de Estado-Nación lleva a plantearse la conveniencia de .alejarse de términos tradicionales, como ius soli o ius sanguinis a la hora de establecer un vínculo entre una persona y un Estado, a favor de otros conceptos como ius connectionis o país con el que una persona mantiene unos vínculos más estrechos y efectivos. Véase, R. Arenas García, "La incompatibilidad del Derecho español con le comunitario en materia de reagrupación de familiares de comunitarios (Comentario a la STJCE (Sala 2a) de 14 de abril de 2005)", La Ley UE, ${ }^{\circ}$ 6350, 2005, 1-5, p. 2.

${ }^{44}$ A pesar de su diferente filiación histórica y funcionalidad política, (el primero vinculado a la transmisión de la ciudadanía ateniense o romana y el segundo a la transmisión de la condición de súbdito en época feudal y de natural durante el absolutismo).

Araucaria. Revista Iberoamericana de Filosofía, Política, Humanidades y Relaciones Internacionales, año 20, $\mathrm{n}^{\circ} 40$ Segundo semestre de 2018. Pp. 453-481. ISSN 1575-6823 e-ISSN 2340-2199 doi: 10.12795/araucaria.2018.i40.21 
sin nacionales, y que el ser nacional conforma el estatuto de sujeto con derechos y perteneciente, como parte del poder constituyente, a la ciudadanía plena ${ }^{45}$.

Lo que parece claro es que los Estados deben actuar de forma no arbitraria, siguiendo criterios razonables y objetivos. Además, el estatus migratorio no puede ser condición para el otorgamiento de la nacionalidad por ius soli. Centrémonos por un instante en la regulación española.

En España, como en el resto de países de la UE, el criterio general de atribución de la nacionalidad es el ius sanguinis ${ }^{46}$. No obstante, de acuerdo con lo preceptuado en el artículo 17.1 (apartados b, c y d) del Código Civil, al nacido en España se le atribuye la nacionalidad española, aunque sus padres sean extranjeros si, al menos, uno de ellos, hubiera nacido también en España o si ambos carecieren de nacionalidad o si la legislación de ninguno de ellos atribuye al hijo una nacionalidad, o si su filiación no resulta determinada. En ningún caso se requiere que alguno de los padres esté en situación legal. Es más, en la ley de extranjería española se contempla una autorización residencia por circunstancias excepcionales específica, para el padre o la madre en situación irregular de un menor español, el llamado arraigo familiar ${ }^{47}$. Por tanto, España en este punto aprueba y supera con creces el "test de exigencias" del Derecho internacional, en concreto del artículo 1 del Convenio de Naciones Unidas de 1961 para reducir los casos de apatridia, es el que establece la atribución de la nacionalidad por ius soli a los nacidos de filiación desconocida, o en aquellos casos en que no tengan atribuida otra nacionalidad de origen y exista el riesgo de apatridia.

\section{B. Jurisprudencia del Tribunal Europeo de Derechos Humanos y del Tribunal de Justicia de la Unión Europea}

El estudio realizado hasta ahora se completa, del lado europeo, con el análisis de varios pronunciamientos tanto del Tribunal Europeo de Derechos Humanos (TEDH) como del Tribunal de Justicia de la Unión Europea (TJUE). Si bien es cierto que este último no tiene como una de sus funciones principales la protección del sistema europeo de Derechos Humanos, sí resulta esencial su labor limitadora de competencia exclusiva de los Estados miembros de la UE

\footnotetext{
${ }^{45}$ A. Rubio Castro y M. Moya Escudero, "Nacionalidad y ciudadanía: una relación...”, loc. cit, p. 132.

${ }^{46}$ El último país en acatar este principio fue Irlanda en el año 2004, a raíz de la STJUEde 19 de octubre de 2004, As. C-200/02, Chen \& Zhu v. Secretary of State of the Home Department.Vid. infra.

${ }^{47}$ Véase en concreto el artículo 124.3 del Real Decreto 557/2011, de 20 de abril, por el que se aprueba el Reglamento de la Ley Orgánica 4/2000, sobre derechos y libertades de los extranjeros en España y su integración social, tras su reforma por Ley Orgánica 2/2009 (BOE núm. 103 de 30 de Abril de 2011). Para un estudio de este precepto véase: D. Marín Consarnau, "Luces y sombras del arraigo familiar como solución a la situación de los progenitores extranjeros de menores españoles", Políticas migratorias, asilo y derechos humanos: un cruce de perspectivas entre la Unión Europea y España, Ed. Universidad de Valencia, 2014, pp. 395-422;
} 
en materia de nacionalidad. De ahí nuestro interés en estudiar algunos casos relevantes relacionados con este aspecto.

\begin{abstract}
Una de las Sentencias más recientes del TEDH es la de la Gran Sala de 24 de mayo de 2016: el caso Biao c. Dinamarca, que versa sobre la discriminación sufrida por los demandantes por motivos de origen étnico y nacionalidad ${ }^{48}$. En este asunto, el mayor interés se ha centrado por parte del Tribunal a la hora de apreciar si una diferencia de trato de las personas en situaciones similares es discriminatoria cuando carece de justificación objetiva y razonable en un ámbito reservado a la soberanía estatal como es la nacionalidad.
\end{abstract}

Los hechos pueden resumirse de la siguiente manera: el primer demandante, de origen togolés, obtuvo la nacionalidad danesa en el año 2002, tras haber estado residiendo en dicho país desde el año 1993. En el año 2003 contrajo matrimonio con la segunda demandante, de origen y nacionalidad ghanesa. Tras dicho matrimonio, la segunda demandante solicitó un permiso de residencia en Dinamarca, el cual fue rechazado por las autoridades con base en una ley de extranjería que contenía como requisito esencial para otorgar el permiso que la pareja que solicitara la reunificación "no tuviera otros lazos más fuertes con otro país". Este requisito, no obstante, no era necesario en aquellos casos en los que el nacional danés miembro de la pareja hubiera poseído dicha nacionalidad durante más de 28 años (la conocida como "regla de los 28 años").

Los demandantes acudieron ante el TEDH alegando que dicha regla suponía un trato diferente entre los nacionales con nacionalidad danesa durante más de 28 años y aquellos nacionales que hubieran estado disfrutando de ella por un menor tiempo, lo cual constituía un trato discriminatorio en contravención de los artículos 8 y 14 del CEDH.El TEDH observó que la mencionada "regla de los 28 años" tenía como consecuencia una discriminación indirecta que favorecía a aquellos nacionales daneses de origen y perjudicaba de manera desproporcionada a aquellas personas que habían obtenido la nacionalidad por naturalización. El Tribunal considera que, a la luz de los estándares y desarrollos internacionales, es difícil justificar un trato diferenciado. Además, recalcó que, aunque los Estados miembros del Consejo de Europa tenían regímenes diferentes en relación con la reunificación familiar, ninguno de los 29 Estados estudiados realizaba una distinción de sus nacionales a la hora de otorgar o no el derecho a la reunificación familiar.

La "regla del arraigo" a la que alude el ordenamiento interno danés es desfavorable para un grupo minoritario $\mathrm{y}$, por tanto, el hecho de que tengan que transcurrir veintiocho años para poder reagrupar al cónyuge no es neutral y provoca efectos discriminatorios sobre un grupo de ciudadanos daneses con origen étnico distinto, llegando a ser éstos considerados como ciudadanos de

${ }^{48}$ Caso Biao c. Dinamarca, no $28590 / 10$, de 25 de marzo de 2014. 
"segunda clase" y con unos "efectos desproporcionadamente perjudiciales sobre un determinado grupo" que no podría desarrollar su vida familiar en el país de su nacionalidad. Aunque los Estados tienen un amplio margen para demostrar la razonabilidad de una medida discriminatoria, en este caso el TEDH concluye afirmando que se han conculcado tanto el artículo 8 como el 14 de la Convención, con respecto a ambos solicitantes y que el Gobierno danés no pudo justificar la existencia de razones importantes y de peso no relacionadas con el origen étnico de la persona. Al fin y al cabo, esta violación se refiere a todos los ciudadanos daneses de origen extranjero y sus cónyuges extranjeros que puedan encontrarse en una situación desafortunada similar a la de los demandantes $^{49}$. La regla del arraigo de los 28 años no es neutral atendiendo a los efectos de una medida general sobre el grupo de ciudadanos daneses con origen étnico que va más allá incluso de los evidentes impactos individuales. De hecho, como sostiene la opinión disidente tal medida legislativa tiene "efectos desproporcionadamente perjudiciales sobre un determinado grupo" que no podría desarrollar su vida familiar en el país de su nacionalidad llegando a tener una merma en el ejercicio de los derechos dada su consideración como ciudadano danés" $" 50$.

La mayoría de los Estados han establecido la posibilidad de que personas que no tenían originalmente su nacionalidad puedan adquirirla, en general mediante una declaración de voluntad manifestada previo cumplimiento de ciertas condiciones. La nacionalidad, en estos casos, surge de un hecho voluntario que persigue vincular a quien lo exprese con una determinada sociedad política, su cultura, su manera de vivir y su sistema de valores. Dado que el otorgamiento de la nacionalidad cae dentro de las competencias del Estado soberano, éste puede establecer cuáles son los requisitos que deben cumplir los extranjeros que aspiren a obtener la naturalización. Los Estados gozan a este respecto de un cierto margen de apreciación.

Por lo que respecta al TJUE, no es este el lugar para revisar su extensa y en ocasiones conflictiva jurisprudencia en el ámbito de la ciudadanía europea, pero sí es preciso citar algunos de los pronunciamientos más importantes, sobre todo aquellos que establecen límites a la competencia exclusiva de los Estados en materia de nacionalidad. El Tribunal luxemburgués ha tenido oportunidad de pronunciarse en múltiples ocasiones sobre dichos límites y a pesar de que ha hecho una interpretación de la normativa, respetuosa siempre con la competencia estatal en materia de nacionalidad, no han faltado decisiones que

\footnotetext{
${ }^{49}$ A. Martín Villegas, "La jurisprudencia del Tribunal Europeo de Derechos Humanos en materia de reagrupación familiar", Aequalitas: Revista jurídica de igualdad de oportunidades entre mujeres y hombres, $\mathrm{n}^{\circ} 38,2015$, pp. 20-28.

${ }^{50}$ Párrafo 8 del voto disidente de los jueces Sajó, Vučinič and Kūris, citado por E. LA SPINA, "Diferentes pautas interpretativas para la admisión de familiares extranjeros en la jurisdicción regional europea", Revista de Estudios Jurídicos nº 14, 2014, pp. 1-24, p.12.
}

Araucaria. Revista Iberoamericana de Filosofia, Política, Humanidades y Relaciones Internacionales, año 20, $\mathrm{n}^{\circ} 40$. Segundo semestre de 2018. Pp. 453-481. ISSN 1575-6823 e-ISSN 2340-2199 doi: 10.12795/araucaria.2018.i40.21 
han buscado su adaptación funcional a unos objetivos comunes, presididos por los Derechos fundamentales consagrados en la CDFUE.

La relación entre la ciudadanía de la Unión y las nacionalidades de los Estados miembros no es siempre pacífica y "si en sus inicios despertó ciertas suspicacias, andado el tiempo ha suscitado considerables incertidumbres sobreel alcance del poder discrecional de los Estados para regular su propia nacionalidad" 51 . No obstante, el grado real de autonomía del que disponen los Estados miembros en la regulación de su nacionalidad es una cuestión cada vez más controvertida ${ }^{52}$. Los elementos que tradicionalmente han delimitado la discrecionalidad de los Estados miembros en la regulación de la nacionalidad se han modificado como consecuencia de la aparición de un conjunto de principios internacionales y mecanismos legales y judiciales de supervisión o monitorización de las actuaciones de dichos Estados en materia de nacionalidad ${ }^{53}$. El grado de autonomía del que han venido disfrutando los Estados miembros de la UE ha sido remodelado de forma progresiva.

Los fallos del TJUE en este ámbito tienen una base común: aunque los Estados miembros tienen competencia exclusiva para legislar en materia de Derecho de nacionalidad, esta regulación puede afectar a la libre circulación de personas ${ }^{54}$. Baste recordar el famoso asunto Micheletti en la que el Alto Tribunal afirmó que "la determinación de los modos de adquisición y pérdida de la nacionalidad es, de conformidad con el Derecho internacional, competencia de cada Estado miembro, competencia que debe ejercerse respetando el Derecho

${ }^{51}$ P. Juárez Pérez, "Dieciocho años de ciudadanía de la Unión: ¿Hacia una figura emancipada?”, Cuadernos de Derecho Transnacional, vol. 2, núm. 2, 2010, pp. 261-289, P. 261.

52 J. Shaw, "Has the European Court of Justice Challenged Member State sovereignty in Nationality Law?”, EUIWorkingPapers, RSCAS 2014/01, Observatorio de la Ciudadanía EUDO, Florencia, 2011.

${ }_{53}$ S. Carrera Núñez y G. Marrero González, "La ciudadanía europea en venta. El programa de venta de la nacionalidad maltesa: ¿una brecha en el principio de cooperación leal en el ámbito de ciudadanía de la unión?", Revista de Derecho Comunitario Europeo, núm. 49, Madrid, septiembre/diciembre, 2014, pp. 847-885, p. 849.

${ }_{54}$ Así lo ha puesto de manifiesto incluso el Parlamento Europeo en el "Rapport fait au nom de la commission juridique sur le projet de loi sur la nationalité britannique". Doc. I-254/81 de 10 de junio. Documents de Séance, 1098-1982. La British Nationality Act creaba situaciones en las que personas nacidas de padres británicos en otro Estado miembro no podrían transmitir automáticamente la nacionalidad británica a sus descendientes si éstos llegaban a nacer también fuera del Reino Unido. Impedía a la segunda generación de británicos nacidos fuera del Reino Unido la atribución de esa nacionalidad. Y, teniendo en consideración la legislación sobre nacionalidad del resto de los Estados miembros, ello suponía la posibilidad de que esa segunda generación no tuviera nacionalidad alguna. El Parlamento destacó que esto podía aumentar los casos de apatrídia, y además limitar la libre circulación de trabajadores en la Comunidad, ante los problemas en la adquisición de la nacionalidad británica para los descendientes de los trabajadores que la ejercieran. En definitiva, el Parlamento no puso en duda que los criterios de atribución de la nacionalidad británica correspondieran en exclusiva al Reino Unido, pero la regulación establecida incidía en el Derecho comunitario y, en concreto, en uno de sus principios básicos: la libre circulación de personas. A pesar de que la nacionalidad no era un ámbito propio del Derecho comunitario, y por ello el legislador no estaba obligado a considerarlo para redactar sus normas sobre nacionalidad, la vinculación o relación que la nacionalidad presentaba con la inmigración, afectaba al sector comunitarizado de la libre circulación de personas.

Araucaria. Revista Iberoamericana de Filosofía, Política, Humanidades y Relaciones Internacionales, año 20, $\mathrm{n}^{\circ} 40$. Segundo semestre de 2018. Pp. 453-481. ISSN 1575-6823 e-ISSN 2340-2199 doi: 10.12795/araucaria.2018.i40.21 
comunitario". Pero añadió que "no corresponde en cambio a la legislación de un Estado miembro limitar los efectos de la atribución de la nacionalidad de otro Estado miembro, exigiendo requisitos adicionales para reconocer dicha nacionalidad en orden al ejercicio de las libertades fundamentales previstas en el Tratado" $" 55$.

Con posterioridad a este asunto el TJUE se ha pronunciado sobre este particular en multitud de ocasiones ${ }^{56}$. Se analizan como casos más representativos de esta línea jurisprudencial las Sentencias Chen\&Zhu $u^{57}$ y Rottmann ${ }^{58}$ en las que se pone de manifiesto la relación causal entre la atribución y adquisición de la nacionalidad de un Estado miembro y la ciudadanía de la UE.

En el asunto Chen\&Zhu, el TJCE resuelve la petición de una nacional china (la Sra. Chen), madre de un niño de la misma nacionalidad, que viajó a Belfast,Irlanda del Norte, para dar a luz a su segunda hija (Catherine).

\footnotetext{
${ }^{55}$ Sentencia de 7 de julio de 1992, M.V. Micheletti yotros v. Delegación del Gobierno en Cantabria (C369/90). El Sr. Micheletti, nacional italo-argentino, cuya última residencia habitual se había encontrado en Argentina, solicitó el permiso de residencia en España como nacional italiano. La Administración española entendió que, por aplicación del artículo 9.9 del Código Civil español, la nacionalidad efectiva del solicitante era la argentina, por lo que no accedió a lo solicitado. En estas circunstancias, se plantea al Tribunal una cuestión prejudicial sobre si la competencia estatal en materia de nacionalidad abarcaba también la capacidad de determinar cuál es la nacionalidad efectiva de quien ostenta más de una, cuando al menos una de ellas es la de un Estado de la Unión. Vid. D. RUZIÉ, "Nationalité, efectivité et droit communautaire", Revue Genérale de Droit International Public, 1993, pp. 107-120; y los comentarios a la Sentencia de A. Borrás Rodríguez, Revista Jurídica de Catalunya, 1993, pp. 584-587; H.U. Jessurun D'Oliveira, Common Market Law Review, 1993, pp. 623-637; J. L. Iglesias Buhigues, "Nota a la STJCE de 7 de julio de 1992, as. C-369/90, Micheletti,Hacia un nuevo orden internacional y europeo. Estudios en homenaje al Prof. Diez de Velasco, Tecnos, Madrid, 1993, pp. 953-967; J. M. Espinar Vicente, La Ley Comunidades Europeas, no 84, 1993, pp. 1-5; N. Bouza I Vidal, Revista de Instituciones Europeas, 1993, pp. 563-581. De todas formas el asunto Micheletti no fue el primero en tratar esta cuestión. Entre otras pueden consultarse la STJCE de 20 de febrero de 1975, as. C-21/74, Airola, STJCE de 20 de febrero de 1975, as. C-37/74, Van den Broeck; STJCE de 14 de diciembre de 1979, as. C-257/78, Kenny-Levick.

${ }^{56}$ STJCE de 2 de octubre de 2003, As. C-148/02, Carlos García Avello c. ÉtatBelge; Vid. A. Lara Aguado, A., "Libertades comunitarias, doble nacionalidad y régimen de los apellidos (Caso García Avello y el avance irresistible de la autonomía de la voluntad)", La Ley, núm. 6107, 15 de octubre de 2004, pp. 1-6; STJUE de 8 de marzo de 2011, Zambrano, As. C- 34/09;Vid. K. Hailbronner, D. Thym, "Ruiz Zambrano: Die Entdeckung des Kernbereichs der Unionsbürgerschaft", Neue Juristische Wochenschrift, Vol. 64, №. 28, 2011, pp. 2008-2014STJUE (Gran Sala) de 14 de noviembre de 2017. Asunto C-165/16 (Lounes). Vid. comentario de P. Jiménez Blanco, "Doble nacionalidad y derecho de residencia de los miembros de la familia del ciudadano de la Unión", La Ley Unión Europea, $\mathrm{N}^{\circ}$ 56, 28 de Febrero de 2018.

${ }^{57}$ STJCE de 19 de octubre de 2004, As. C-200/02, Chen \& Zhu v. Secretary of State of the Home Department. Vid. J. Ferrer Lloret, "El ejercicio de los derechos de la ciudadanía de la UE: libre circulación y residencia. Comentario a la Sentencia del TJCE de 19 de octubre de 2004 (Chen contra Secretary of the Home Department, asunto C-200/02)", Revista General de Derecho Europeo, no 6, de 6 de enero de 2005, disponible previa suscripción en www.iustel.com; D. Liakopoulos, "La condizione giuridica dello straniero: evoluzione del concetto di cittadinanzaalla luce delle norme internazionali", www.immigrazioneelavoro.it/public/im.pdf., 2005, pp. 1-19; T. Ballarino Y B. UBERTAZZI, "On Avello and Other Judgements: A New point Of Departure in the Consflicts of Laws?", Yearbook of Private International Law, Vol. VI, 2004, pp. 85-128, pp.107-110; B. Kunoy, "A Union of National Citizens: The Origins of the Courts Lack of Avant-Gardisme on the Chen Case", Common Market Law Review, núm. 43, 2006, pp. 179-190.

${ }^{58}$ STJUE (Gran Sala) de 2 de marzo de 2010, Janko Rottman c. Freistaat Bayern, asunto C-135/08.
} 
Ésta adquirió la nacionalidad irlandesa, ya que la normativa de este país permitía en ese momento adquirir esta nacionalidad a toda persona que naciera en la isla (lo que incluye el territorio de Irlanda del Norte, bajo la soberanía del Reino Unido) en unas condiciones determinadas. En cambio, Catherine no adquirió la nacionalidad británica al no reunir los requisitos necesarios ${ }^{59}$. Posteriormente, la Sra. Chen se trasladó con sus hijos a Cardiff (Reino Unido), donde se negaron a concederles un permiso de residencia de larga duración. Tal negativa se basaba, por una parte, en que Catherine, de ocho meses de edad, no tenía capacidad para ejercer autónomamente ningún derecho derivado del Tratado CE, y, por otra, en que la Sra. Chen no estaba autorizada a residir en el Reino Unido con arreglo a la normativa comunitaria, puesto que era nacional de un tercer Estado. Se interpuso recurso contra tal resolución ante la Immigration Appellate Authority, que fue la que planteó la cuestión prejudicial ${ }^{60}$.

El Gobierno del Reino Unido alegó en este caso, que el traslado de la señora Chen a Irlanda del Norte para que su hija adquiriera la nacionalidad irlandesa constituía un intento de utilizar de forma abusiva las normas UE, a lo que el TJCE respondió que la determinación de los modos de adquisición y pérdida de la nacionalidad es competencia de cada Estado miembro. No se discute que la estancia en Irlanda tenía como único objeto permitir que la niña que iba a nacer adquiriera la nacionalidad irlandesa ${ }^{61} \mathrm{y}$, en consecuencia, que se le reconociera, en su caso, a la madre, el derecho a residir con su hija en el territorio del Reino Unido. En Irlanda, hasta el 24 de junio de 2004, uno de los modos de adquisición de la nacionalidad era el simple hecho del nacimiento en la isla ${ }^{62}$. Dicho país era el único de la UE que mantenía el criterio del ius

${ }^{59}$ La normativa aplicable está recogida en la British Nationality Act de 1981.

${ }^{60}$ Para un análisis más detallado véase, M. Soto Moya, "La libre circulación de personas como concepto ambivalente”, Revista Española de Derecho Internacional, 2008, pp. 163-178.

${ }^{61}$ Aunque el TJCE no lo hace, en sus conclusiones, el Abogado General Tizzano sí entra a analizar el asunto desde la posible aplicación de la noción de abuso del derecho. A su entender, para que esta figura pueda ser aplicada, con carácter muy excepcional en el ámbito comunitario por la propia naturaleza de las relaciones entre este ordenamiento y los ordenamientos internos de los Estados miembros, "el criterio de referencia consiste básicamente en determinar si se ha producido una distorsión de la finalidad y de los objetivos de la norma comunitaria que confiere el derecho controvertido" (párrafo 112). Según el Abogado General "no estamos ante personas que se acogen abusiva o fraudulentamente al Derecho comunitario, distorsionando el alcance y la finalidad de las normas de dicho ordenamiento, sino ante personas que, conociendo el contenido de las libertades establecidas por el Derecho comunitario, las invocan, con medios legítimos, precisamente para conseguir el objetivo que la normativa comunitaria pretende garantizar, a saber, el derecho de residencia de la niña (párrafo 122 ).

${ }^{62}$ Así lo establecía la Irish Nationality and Citizenship Act, 1956 (No. 26 of 1956), en su art. 6.2: "Every person born in Ireland is an Irish citizen from birth."Irlanda era el único país de la UE que mantenía el criterio del ius soli puro, sin necesidad de acreditar ningún otro requisito,para otorgar la nacionalidad. La consecuencia es que ha existido un tipo de inmigación específica de nacionales de terceros Estados cuyos hijos han nacido en Irlanda y a los que se les ha atribuido la nacionalidad irlandesa, mientras que sus progenitores seguían siendo nacionales de terceros Estados y, evidentemente, en la mayoría de los casos, en situación irregular.

Araucaria. Revista Iberoamericana de Filosofía, Política, Humanidades y Relaciones Internacionales, año 20, $\mathrm{n}^{\circ} 40$. Segundo semestre de 2018. Pp. 453-481. ISSN 1575-6823 e-ISSN 2340-2199 doi: 10.12795/araucaria.2018.i40.21 
soli puro, sin necesidad de acreditar ningún otro requisito,para otorgar la nacionalidad ${ }^{63}$.

La consecuencia es que ha existido un tipo de inmigación específica de nacionales de terceros Estados cuyos hijos han nacido en Irlanda y a los que se les ha atribuido la nacionalidad irlandesa, mientras que sus progenitores seguían siendo nacionales de terceros Estados y, evidentemente, en la mayoría de los casos, en situación irregular ${ }^{64}$. Es necesario poner de relieve que la atribución de la nacionalidad por ius soli no solo causaba "problemas internos" en Irlanda, sino también externos, en el Reino Unido, ya que al pertenecer ambos a la Common Travel Area, los nacionales irlandeses y británicos pueden circular y residir libremente en el territorio de sus respectivos Estados, además del hecho obvio de que Irlanda del Norte pertenece al Reino Unido. Los problemas aparecen cuando los nacionales de terceros Estados se desplazan con sus hijos irlandeses al Reino Unido, y solicitan residir allí, como en el caso Chen\&Zhu.

La solución adoptada por Irlanda fue cambiar su legislación por lo que respecta a los modos de atribución de la nacionalidad. El 24 de junio de 2004 se modificó el artículo 9.2 de la Constitución irlandesa que establece ahora que una persona nacida en Irlanda no será irlandesa si en el momento de su nacimiento no tiene un progenitor de nacionalidad irlandesa o con el derecho a tenerla. Esta decisión no es una consecuencia directa de la sentencia del TJCE, pero sí es una de las circunstancias, junto a las demás expuestas, que han dado lugar a la transformación del ordenamiento jurídico irlandés. Si bien es cierto que la regulación del Derecho de nacionalidad es una competencia exclusiva de cada Estado miembro, las decisiones del TJCE pueden influir indirectamente en su transformación, como ha ocurrido con Irlanda.

En cuanto al segundo de los asuntos al que íbamos a hacer referencia, Rottmann, la cuestión estribaba en determinar, en esencia, si el Derecho de la Unión Europea se opone a que un Estado miembro le revoque a un ciudadano de la Unión la nacionalidad de dicho Estado miembro adquirida de modo fraudulento mediante naturalización. En este asunto tal revocación privaba al interesado de su estatuto de ciudadano de la Unión y de los derechos correspondientes, convirtiéndolo en apátrida, puesto que la adquisición de la nacionalidad de ese Estado miembro por naturalización supuso para la persona

\footnotetext{
${ }^{63}$ Para un análisis del denominado "Birthright Citizenship" vid. A. GROSSMAN, "Birthright Citizenship as Nationality of Convenience", Proceedings, Council of Europe, Third Conference on Nationality, Strasbourg, 11-12 octubre 2004.

${ }^{64}$ La IrishSupremeCourt había entendido, desde el caso Fajujonu(Irish Supreme Court Judgement, de 8 de diciembre de 1989, Fajujonu v. MinisterforJustice and Another), que los menores tenían un derecho constitucional a la compañía y el cuidado de sus progenitores en Irlanda, y por tanto, aunque éstos fueran nacionales de terceros Estados, era necesario concederles un derecho de residencia en la isla. Pero este planteamiento cambió en 2003 con la Sentencia Lobe and Osayande (IrishSupremeCourtJudgement, de 28 de enero de 2003, Lobe\&Ors - v- MinisterforJustice, Equality\&LawReform, Osayande\&anor-v-MinisterforJustice, Equality\&Law and ors).
} 
afectada la pérdida de la nacionalidad de su Estado miembro de origen. En concreto, se trata de un nacional austriaco que solicita la nacionalidad alemana por naturalización. La nacionalidad alemana le es concedida, lo que supone la pérdida de la nacionalidad austriaca. El problema se encuentra en que en el momento de la solicitud de su nueva nacionalidad el Sr. Rottmann evita mencionar su condición de imputado en un procedimiento de estafa grave en Austria. A raíz de dicho procedimiento se dicta una orden de detención nacional que comporta la revocación de su naturalización por obtención fraudulenta de la nacionalidad alemana. La revocación de la nacionalidad alemana y la no restitución de la austriaca, por no darse los requisitos necesarios para ello, pueden convertir al señor Rottmann en apátrida.

El punto más conflictivo es quizás la determinación de si una decisión revocatoria de la naturalización de la nacionalidad de un ciudadano de la Unión puede ser sometida a control jurisdiccional en la medida que es susceptible de afectar a derechos conferidos y protegidos por el Derecho europeo. Recuerda una vez más el TJUE que los Estados miembros son competentes para determinar los modos de adquisición y pérdida de la nacionalidad. Pero, acto seguido, consagra el principio según el cual, cuando se trata de ciudadanos de la Unión, el ejercicio de esta competencia, en la medida en que afecte a los derechos conferidos y protegidos por el ordenamiento jurídico de la Unión, como ocurre en particular en el caso de una decisión revocatoria de la naturalización, puede ser sometido a un control jurisdiccional realizado en función del Derecho de la Unión. En concreto, esta decisión deberá respetar el principio de proporcionalidad. La emisión de una decisión "desproporcionada" podría declararse contraria al Derecho de la Unión. El Tribunal ofrece, a modo de ejemplo, determinados elementos que pueden ser tomados en consideración por los órganos jurisdiccionales nacionales para proceder al examen de la proporcionalidad. El Tribunal estima necesaria la consideración de las consecuencias de la decisión de revocación para el interesado y para los miembros de su familia. En particular, la medida revocatoria ha de justificarse en relación con la gravedad de la infracción, con el tiempo trascurrido entre la decisión de naturalización y su posterior revocación, así como con la posibilidad de que el interesado recupere su nacionalidad de origen, explicitando que la ausencia de recuperación de la nacionalidad de origen no conlleva obligación para el Estado de naturalización de abstenerse de proceder a la revocación. Finalmente, el Tribunal aporta una propuesta de solución práctica, consistente en el otorgamiento al afectado por parte del órgano jurisdiccional del Estado de la revocación de un plazo razonable para intentar la recuperación de su nacionalidad de origen ${ }^{65}$.

\footnotetext{
${ }^{65}$ Apartado 58 de la Sentencia.
} 
Con esta sentencia el TJUE decide dar un paso más en la capacidad del Derecho europeo de interferir en la aplicación de las normas de los Estados miembros en materia de adquisición y pérdida de la nacionalidad ${ }^{66}$. Esta interpretación implica la imposición de límites por parte del Derecho de la Unión no únicamente a las situaciones de pérdida de la nacionalidad estatal, sino también con respecto a la normativa nacional de adquisición de la misma. La propia sentencia indica que los principios en ella enunciados se aplican también con respecto a la readquisición de la nacionalidad en el Estado miembro de origen ${ }^{67}$. De afianzarse esta interpretación, el Derecho de la Unión cobraría relevancia en relación con determinados desarrollos normativos problemáticos en materia de nacionalidad que se están produciendo en algunos países de la UE. Nos referimos, por ejemplo, al Programa Chipriota para la Naturalización de Inversores ${ }^{68}$, o al programa no oficial de naturalización para inversores que se negocia con los candidatos caso por caso de Austria ${ }^{69}$. Bulgaria cuenta también con un programa de naturalización para inversores aprobado en febrero de $2013^{70}$. Pero el caso más flagrante fue el Programa Maltés para Inversores Individuales, que al final no llegó a implementarse. Establecía que cualquier extranjero que realizara una donación al Estado o invirtiera una cantidad sustancial de capital en el país, sin ningún otro requisito adicional, podía adquirir la nacionalidad de Malta. En todos estos casos, la venta de la nacionalidad se transforma también en la venta de la ciudadanía europea.

Por este motivo, la Comisión y el Parlamento Europeos se han visto obligados a intervenir en asuntos que en principio son privativos de los Estados miembros. La Comisión, a través de su vicepresidenta en un discurso titulado "La ciudadanía no debe venderse", indicó que las decisiones adoptadas por un Estado miembro relativas a la naturalización o concesión de su nacionalidad "no son neutrales" con respecto a los demás Estados miembros y a la UE en su conjunto, afirmando que en ningún caso debe ponerse un precio a la ciudadanía de la Unión ${ }^{71}$. Y el Parlamento ha intervenido adoptando una Resolución sobre la Ciudadanía de la UE en la que se condenan los programas de venta

${ }^{66}$ N. Magallón Elósegui, “Ciudadanía de la Unión”, Revista Española de Derecho Internacional, vol. XLII, 2010, pp. 197-200, p. 198.

${ }^{67}$ S. Iglesias Sánchez, “Hacia una nueva relación entre la nacionalidad estatal y la ciudadanía europea?”, Revista de Derecho Comunitario Europeo, núm. 37, Madrid, septiembre/diciembre 2010, págs. 933-950, p. 942.

${ }^{68}$ Cypriot Scheme for Naturalisation of Investors, adoptado por el Consejo de Ministros el 24 de mayo de 2013.

${ }^{69}$ Artículo 10.6 de la Ley Federal reguladora de la Nacionalidad Austriaca (Ley de Nacionalidad, 30 de julio de 1985, Federal LawGazette de la República de Austria, FLG, No. 311/1985).

${ }^{70}$ Para un análisis en profundidad de todos estos programas de venta de la nacionalidad puede verse, S. Carrera Núñez y G. Marrero González, "La ciudadanía europea en venta. El programa de venta de la nacionalidad maltesa...", loc. cit.

${ }^{71}$ V. Reding, "Citizen ship must not be up for sale", Comisión Europea, Discurso/ 14/18, 15 de enero de 2014.

Araucaria. Revista Iberoamericana de Filosofia, Política, Humanidades y Relaciones Internacionales, año 20, $\mathrm{n}^{\circ} 40$. Segundo semestre de 2018. Pp. 453-481. ISSN 1575-6823 e-ISSN 2340-2199 doi: 10.12795/araucaria.2018.i40.21 
de la nacionalidad de los Estados miembros, recordando que éstos sólo deben conceder la ciudadanía a aquellas personas que tengan un "vínculo efectivo" o una "conexión genuina" con el país de que se trate.

\section{Conclusiones}

A pesar de que la consideración de la nacionalidad como derecho humano no es una cuestión del todo pacífica, lo que resulta obvio es que, tanto los instrumentos internacionales de protección de los derechos humanos, como los propios tribunales encargados de controlar su efectiva aplicación, están limitando la competencia exclusiva de los Estados por lo que se refiere a la atribución, adquisición o pérdida de aquella. La determinación de quiénes son nacionales sigue siendo competencia interna de los Estados. Sin embargo, su discrecionalidad en esa materia sufre un constante proceso de restricción conforme a la evolución del Derecho internacional, con vistas a una mayor protección de la persona frente a la arbitrariedad de los Estados.

Para poner de relieve el difícil equilibrio entre la soberanía de los Estados y la garantía universal de los derechos, se ha realizado un análisis jurisprudencial de una serie de asuntos que hemos seleccionado por considerarlos trascendentales y que por su importancia desbordaban las peculiaridades del caso concreto. En ellos se interpretan y aplican las normas contenidas en los instrumentos internacionales de protección de los derechos humanos y, en el caso del TJUE, la normativa de la UE que afecta al derecho de libre circulación de personas y a la ciudadanía europea. De su estudio hemos extraído varias conclusiones:

1. Tanto la CIDH como el TEDH y el TJUE, han puesto ciertos límites a la soberanía estatal, considerando la nacionalidad como un derecho humano, estableciendo que los Estados tienen la obligación de no adoptar prácticas o legislación, respecto al otorgamiento de la nacionalidad, cuya aplicación favorezca el incremento del número de personas apátridas, condición que es derivada de la falta de nacionalidad.

2. Por lo que respecta a la atribución de la nacionalidad ex lege, los Estados no están obligados a acatar el criterio del ius soli. Pueden establecer libremente los criterios bajo los cuales reconocen la nacionalidad. El régimen constitucional y legal de cada Estado puede aceptar indistintamente el principio del ius soli o del ius sanguinis, o mezclarlos. Lo que parece claro es que los Estados deben actuar de forma no arbitraria, siguiendo criterios razonables y objetivos. Además, el estatus migratorio no puede ser condición para el otorgamiento de la nacionalidad por ius soli. 
3. En cuanto a la adquisición de la nacionalidad, de los asuntos analizados se colige que los Estados pueden legislar utilizando políticas que establezcan requisitos menos estrictos para aquellos nacionales de países que compartan lazos históricos comunes. El hecho de que una determinada reforma responda a una reacción nacionalista, a una tendencia regresiva frente al espíritu tradicionalmente humanitario de un sistema jurídico, o a un rechazo a una tradición de unidad de determinados pueblos, es perfectamente factible. Se trata de cuestiones políticas que se incluyen dentro de la competencia del Estado, y que escapan a la consideración estrictamente jurídica a la que ella debe atenerse.

4. Una vez se adquiere la nacionalidad de un determinado Estado por naturalización, no es posible la discriminación con los nacionales de origen, y el TEDH ha sido muy claro a este respecto: a la luz de los estándares y desarrollos internacionales, no hay lugar a dudas de que un Estado no puede discriminar indirectamente a sus propios nacionales basándose en su origen étnico, si no se puede justificar la existencia de razones importantes y de peso. Esta discriminación podría producir unos efectos desproporcionadamente perjudiciales sobre un determinado grupo, mermando el ejercicio efectivo de sus derechos.

5. Para los países de la Unión Europea el equilibrio entre la soberanía de los Estados y la garantía universal de los derechos, es aún más delicado al tener que hacer frente también al control de las instituciones UE y al TJUE. Los fallos del Tribunal luxemburgués en este ámbito tienen una base común: aunque los Estados miembros tienen competencia exclusiva para legislar en materia de Derecho de nacionalidad, esta regulación puede afectar a la libre circulación de personas, ya que la adquisición de la nacionalidad un Estado miembro comporta también la adquisición de la ciudadanía UE.Incluso la Comisión y el Parlamento Europeos se han visto obligados a intervenir en asuntos que en principio son privativos de los Estados miembros, recordando que éstos sólo deben conceder la nacionalidad a aquellas personas que tengan un "vínculo efectivo" o una "conexión genuina" con el país de que se trate. 


\section{Referencias bibliográficas:}

Abramovich, V., "Comentarios sobre "Fontevecchia", la autoridad de las sentencias de la Corte Interamericana y los principios de derecho público argentino", Pensamiento Penal, marzo 2017, pp. 1-17.

Aláez Corral, B.,Nacionalidad, ciudadanía y democracia, Centro de Estudios políticos y constitucionales, Madrid, 2006.

Arenas García, R.,"La incompatibilidad del Derecho español con le comunitario en materia de reagrupación de familiares de comunitarios (Comentario a la STJCE (Sala 2a) de 14 de abril de 2005)", La Ley UE, nº 6350, 2005, pp.1-5. Arletazz, F., "La nacionalidad en el derecho internacional americano", Anuario Mexicano de Derecho Internacional, vol. XV, 2015, pp. 413-447.

Ballarino, T y Ubertazzi, B., "On Avello and Other Judgements: A New point Of Departure in the Consflicts of Laws?", Yearbook of Private International Law, Vol. VI, 2004, pp. 85-128, pp.107-110.

Kunoy, B., "A Union of National Citizens: The Origins of the Courts Lack of Avant-Gardisme on the Chen Case", Common Market Law Review, núm. 43, 2006, pp. 179-190.

Borrás Rodríguez, A., Revista Jurídica de Catalunya, 1993, pp. 584-587.

Bouza I Vidal, N., Revista de Instituciones Europeas, 1993, pp. 563-581.

Carrascosa González, J.,Derecho español de la nacionalidad. Estudio práctico, Comares, Granada, 2011.

Carrascosa González, J., Durán Ayago, A.,y Carrillo Carrillo, B., Curso de nacionalidad y extranjería, Colex, Madrid, 2007.

Carrera Núñez, S. y Marrero González, G., "La ciudadanía europea en venta. El programa de venta de la nacionalidad maltesa: ¿una brecha en el principio de cooperación leal en el ámbito de ciudadanía de la unión?", Revista de Derecho Comunitario Europeo, núm. 49, Madrid, septiembre/diciembre, 2014, pp. 847-885.

De Castro Y Bravo, F., "La nationalité. La doublé nationalité et la supranationalité", Recueil des cours, vol. 102, 1961, pp. 546-550.

Del Rosario Rodríguez, M. F., "El Derecho a la nacionalidad", Revista Internacional de Derechos Humanos, 2011 Año I, no 1, pp. 81-107.

Espinar Vicente, J. M,La nacionalidad y la extranjería en el sistema jurídico español, Civitas, Madrid, 1994, pp. 37-38.

Id. La Ley Comunidades Europeas, no 84, 1993, pp. 1-5.

FerrerLLoret, J., "El ejercicio de los derechos de la ciudadanía de la UE: libre circulación y residencia. Comentario a la Sentencia del TJCE de 19 de octubre de 2004 (Chen contra Secretary of the Home Department, asunto C-200/02)", Revista General de Derecho Europeo, nº 6, de 6 de enero de 2005, disponible previa suscripción en www.iustel.com. 
Id., "El conflicto del Sahara Occidental ante los Tribunales de la Unión Europea", Revista General de Derecho Europeo, núm. 42, 2017, pp. 1564.

Goig Martínez, J. M., "Regularización y naturalización de inmigrantes irregulares en República Dominicana. Estudio de la Sentencia 0168/13 del Tribunal Constitucional dominicano y sus efectos en materia de nacionalidad", Anuario Iberoamericano de Justicia Constitucional, núm. 19, Madrid, 2015, págs. 185-219.

Gómez Recio, F., "Sobre la nacionalidad española de los naturales del Sahara", La Ley, núm. 7333, 2010.

Grossman, A., "Birthright Citizenship as Nationality of Convenience", Proceedings, Council of Europe, Third Conference on Nationality, Strasbourg, 11-12 octubre 2004.

Hailbronner, K. y Thym, D., "Ruiz Zambrano: Die Entdeckung des Kernbereichs der Unionsbürgerschaft", Neue Juristische Wochenschrift, Vol. 64, Nº. 28, 2011, pp. 2008-2014.

Hall, S., "The European Conventionon Nationality and the Right to Have Rights", European Law Review, vol. 24, 1999, pp. 586-602.

IglesiasBuhigues, J. L., "Nota a la STJCE de 7 de julio de 1992, as. C-369/90, Micheletti,Hacia un nuevo orden internacional y europeo. Estudios en homenaje al Prof. Diez de Velasco, Tecnos, Madrid, 1993, pp. 953-967.

Iglesias Sánchez, S., “¿Hacia una nueva relación entre la nacionalidad estatal y la ciudadanía europea?", Revista de Derecho Comunitario Europeo, núm. 37, Madrid, septiembre/diciembre 2010, págs. 933-950.

JessurunD'Oliveira, H. U., Common Market Law Review, 1993, pp. 623-637.

Jiménez Blanco, P., "Doble nacionalidad y derecho de residencia de los miembros de la familia del ciudadano de la Unión", La Ley Unión Europea, $\mathrm{N}^{\mathrm{0}}$ 56, 28 de Febrero de 2018.

Juárez Pérez, P., "Dieciocho años de ciudadanía de la Unión: ¿Hacia una figura emancipada?", Cuadernos de Derecho Transnacional, vol. 2, núm. 2, 2010, pp. 261-289.

La Espina, E., "Diferentes pautas interpretativas para la admisión de familiares extranjeros en la jurisdicción regional europea", Revista de Estudios Jurídicos $\mathrm{n}^{\circ}$ 14, 2014, pp. 1-24.

Lara Aguado, A., "Libertades comunitarias, doble nacionalidad y régimen de los apellidos (Caso García Avello y el avance irresistible de la autonomía de la voluntad)", La Ley, núm. 6107, 15 de octubre de 2004, pp. 1-6.

Liakopoulos, D., "La condizione giuridica dello straniero: evoluzione del concetto di cittadinanza alla luce delle norme internazionali", www. immigrazioneelavoro.it/public/im.pdf., 2005, pp. 1-19. 
Magallón Elósegui, N., "Ciudadanía de la Unión”, Revista Española de Derecho Internacional, vol. XLII, 2010, pp. 197-200.

Marín Consarnau, D., "Luces y sombras del arraigo familiar como solución a la situación de los progenitores extranjeros de menores españoles", Políticas migratorias, asilo y derechos humanos: un cruce de perspectivas entre la Unión Europea y España, Ed. Universidad de Valencia, 2014, pp. 395422.

Martín Villegas, A., "La jurisprudencia del Tribunal Europeo de Derechos Humanos en materia de reagrupación familiar", Aequalitas: Revista jurídica de igualdad de oportunidades entre mujeres y hombres, $\mathrm{n}^{\mathrm{o}} 38$, 2015, pp. 20-28.

Núñez Donald, C., "La jurisprudencia de la Corte Interamericana de Derechos

Humanos frente a la movilidad humana: entre cosmopolitismo y hospitalidad", Universitas, 2018, no 27, pp. 76-109.

Panella, L., La cittadinanza e le cittadinanze nel diritto internazionale, EditorialeScientifica, Napoli, 2008.

Pereira Da Silva, J.,Direitos de Cidadania e Direito à Cidadania. ACIME, Lisboa, 2004, pp. 90-102.

Pérez Milla, J.J.,"Travesía hacia la nacionalidad española: oasis y desiertos en el Sahara”, Revista General de Legislación y Jurisprudencia, 2011, pp. 417-454.

Pérez Vera, E., "La ciudadanía europea en el Tratado de Maastricht. Hacia un Nuevo orden internacional y europeo", Homenaje al Profesor Díez de Velasco, Madrid, Tecnos, 1993, pp. 1123-1148).

Rodríguez Pineau, E., "Identidad y nacionalidad", Anuario de la Facultad de Derecho de Madrid, $\mathrm{n}^{\circ}$ 17, 2013, pp. 207-236.

Rubio Castro, A. y Moya Escudero, M., "Nacionalidad y ciudadanía: una relación a debate”, Anales de la Cátedra Francisco Suárez, no 37, 2003, pp. 105-153.

Ruzié, D., "Nationalité, efectivité et droit communautaire", Revue Genérale de Droit International Public, 1993, pp. 107-120.

Sánchez Lorenzo, S., "Derechos humanos y competencia exclusiva del Estado en materia de nacionalidad (La Sentencia de la Corte Interamericana de Derechos Humanos de 28 de agosto de 2014: caso Personas dominicanas y haitianas expulsadas c. República Dominicana)", REDI, Vol. 67, No. 2 (JULIO-DICIEMBRE 2015), pp. 111-133.

Shaw, J., "Has the European Court of Justice Challenged Member State sovereignty in Nationality Law?", EUI Working Papers, RSCAS 2014/01, Observatorio de la Ciudadanía EUDO, Florencia, 2011. 
Soroet a Liceras, J.,"La problemática de la nacionalidad de los habitantes de los territorios dependientes y el caso del Sáhara Occidental", Anuario español de derecho internacional, $\mathrm{N}^{\circ} 15,1999$, pp. 645-676.

$I d$. "Jurisprudencia española en materia de Derecho internacional público - Comentarios de sentencias - La condición jurídica de los saharauis: nacionalidad, apatridia y asilo", Revista Española de Derecho Internacional, Vol. 66, $\mathrm{N}^{\mathrm{o}}$ 2, 2014, pp. 226-237.

Soto Moya, M., "La libre circulación de personas como concepto ambivalente", Revista Española de Derecho Internacional, 2008, pp. 163-178.

Vargas Gómez-Urrutia, M., "Shalom Sefarad: Una "erensya" envenenada", Parte I y Parte II, Bitácora Millennium DIPr: Derecho Internacional Privado, No. 2, 2015.

Weil, P., "Access toCitizenship: a Comparison of Twenty Five Nationality Laws", Citizenship Today: Global Perspectives and Practices, Washington DC, Carnegie Endowment for International Peace, 2007, pp. 17-35. 
